\title{
PERAN KEPEMIMPINAN TRANSFORMASIONAL TERHADAP KETERIKATAN KERJA PADA KARYAWAN MILENIAL DENGAN VARIABEL KOMUNIKASI SEBAGAI MEDIATOR
}

\author{
Kintan Nurcahya Wailulu ${ }^{1}$, Fransisca I.R Dewi ${ }^{2}$, Rita Markus Idulfilastri ${ }^{3}$ \\ 1Program Studi Psikologi Sains Jenjang Magister, Universitas Tarumanagara, Jakarta \\ Email: kintanwai93@gmail.com \\ ${ }^{2}$ Fakultas Psikologi, Universitas Tarumanagara, Jakarta \\ Email: fransiscar@fpsi.untar.ac.id \\ ${ }^{3}$ Fakultas Psikologi, Universitas Tarumanagara, Jakarta \\ Email: ritamarkus@fpsi.untar.ac.id
}

Masuk : 31-10-2019, revisi: 25-11-2019, diterima untuk diterbitkan : 26-11-2019

\begin{abstract}
ABSTRAK
Keterikatan kerja merupakan isu yang penting dalam suatu organisasi karena hal tersebut berdampak pada produktivitas individu maupun organisasi saat ini. Keterikatan kerja (work engagement) merupakan hubungan relasi individu ataupun kelompok terhadap suatu pekerjaan. Fenomena dalam dunia kerja saat ini masuknya generasi kerja milenial yang cenderung memiliki keterikatan kerja rendah yakni mudah merasakan adanya tekanan dalam pekerjaan hal tersebut berdampak pada penyelesaian tugas. Dalam penelitian ini, keterikatan kerja ditinjau dari segi gaya kepemimpinan transformasional (transformational leadership) dengan komunikasi sebagai mediator. Penelitian ini menggunakan metode purposive sampling sebanyak 371 partisipan karyawan milenial telah mengikuti survey yang dilakukan. Berdasarkan hasil analisa Structural Equation Model (SEM) dan ditemukan bahwa kepemimpinan transformasional memiliki peran yang signifikan terhadap keterikatan kerja dan komunikasi terbukti berperan sebagai mediator.
\end{abstract}

Kata Kunci: keterikatan kerja, kepemimpinan transformasional, komunikasi, karyawan, milenial

ABSTRACT

Work engagement is important issue in organization due to it has an impact on the productivity of individuals or organization performance. Work engagement is relationship of individuals or groups to a job. The phenomenon right now is entry of millennial work generation which tends to have a low work engagement, and easy to feel the pressure in the work and it has an impact on task completion. In this study, work engagement is viewed in terms of transformational leadership style with communication as a mediator. This study used a purposive sampling method with 371 millennial employees who already participated. Based on the analysis of the Structural Equation Model (SEM) found that transformational leadership has a significant role in work engagement and communication is proven to act as a mediator.

Keywords: work engagement, transformational leadership, communication; employees, millennial

\section{PENDAHULUAN}

\section{Latar Belakang}

Keterikatan kerja (work engagement) merupakan hubungan relasi individu ataupun kelompok terhadap organisasi (Bakker \& Leiter, 2010). Keterikatan kerja merupakan isu yang penting dalam suatu organisasi karena hal tersebut berdampak pada produktivitas individu maupun organisasi (Rizkiani \& Sawitri, 2015). Karyawan yang memiliki keterikatan kerja tinggi cenderung melakukan pekerjaan dengan benar dan peduli terhadap jenis pekerjaan. Menurut Schaufeli, Salanova, Roma dan Bakker (2002), keterikatan kerja didefinisikan sebagai keadaan pikiran yang positif, memuaskan, terkait dengan pekerjaan yang ditandai dengan energi dan ketahan mental saat bekerja, dedikasi mengacu pada keterlibatan dalam pekerjaan dan mengalami antusiasme serta tantangan, dan penyerapan yakni mengacu pada sepenuhnya terkonsentrasi dan memiliki kesulitan untuk melepaskan pekerjaan. 
Fenomena yang hangat diperbincangkan dalam organisasi atau perusahaan saat ini yakni adanya percampuran tiga generasi yang mewarnai dunia kerja (McCrindle, 2006). Menurut DelCampo, Haggertyy, dan Haney, (2011) gambaran percampuran tiga generasi yang dimaksud yaitu, generasi Baby Boomers atau yang dikenal dengan sebutan generasi Boomers (kelahiran tahun 1946-1964) memiliki karakteristik daya tahan kerja, idealis, kompetitif, dan setia. Generasi X (kelahiran tahun 1965-1980) memiliki karakteristik mandiri, dan loyal. Sedangkan,generasi Y "Milenial" (kelahiran tahun 1981 - 2000) memiliki karakteristik multitasking, suka dengan tantangan, dan optimis namun disatu sisi generasi Y memiliki kecendrungan untuk keluar dari pekerjaanya dan tentu menimbulkan kerugian bagi organisasi (dikutip dalam Dipo, 2016 p.3). Survei Jobsreet Indonesia tentang katrakteristik milenial, bahwa 66\% milenial cenderung kurang memiliki daya juang dan yakni gemar berpindah kerja kurang dari dua tahun (Priherdityo, 2016, p.6). Selain itu, penelitian yang dilakukan oleh Ansari, Humayon, Hussain, dan Aziz (2017) tentang pekerja milenial menyebutkan bahwa $70 \%$ karyawan milenial merupakan generasi yang mudah dalam berganti pekerjaan dengan dua tahun awal setelah bergabung dari satu tempat (perusahaan) ke perusahaan berikutnya. Penelitian lain dari IDN Research Institute terhadap 1400 karyawan milenial menyebutkan 2-3 tahun merupakan tahun yang ideal bagi milenial untuk bekerja dalam suatu perusahaan (dikutip dalam Folia, 2019 p.2).

Karyawan yang memiliki keterikatan kerja rendah, yakni karyawan akan merasakan adanya tekanan dalam pekerjaan. Adanya tekanan dalam pekerjaan tentu berdampak pada hasil pengerjaan tugas atau pekerjaan tersebut (Bakker \& Leiter, 2010). Disatu sisi, berkaitan dengan karakteristik milenial yang memiliki nilai juang yang rendah karena harapan terkait pengembangan diri dalam suatu organisasi atau pekerjaan. Jika, harapan tersebut tidak bisa terwujud sesuai ekspektasi maka berpengaruh pada keterikatan kerja yang dimiliki oleh milenial. Pada konsep keterikatan kerja menunjukkan hubungan timbal balik yang positif antara karyawan dan organisasi yang mendorong partisipasi karyawan yang lebih dinamis dalam melakukan tugas-tugas yang diberikan kerja (Galpin, Stairs \& Page dalam Song., Kolb., Lee \& Kim, 2012). Menurut Schaufeli dan Bakker (2002) bahwa keterikatan kerja pada dasarnya dipengaruhi oleh dua hal, yaitu model JD-R (Job demand-resources model) yang meliputi beberapa aspek seperti lingkungan fisik, sosial, organisasi, dukungan supervisor, serta feedaback, modal psikologis (psychological capital) meliputi kepercayaan diri (self-efficacy), rasa optimis (optimism), harapan mengenai masa depan (hope), serta resilensi (resilience) akan tetapi keterikatan kerja yang rendah dapat ditingkatkan melalui komunikasi, yakni dengan peran komunikasi internal menujukkan bahwa peran komunikasi internal meningkatkan keterikatan kerja karyawan yakni agar karyawan merasa bahwa mampu berkontribusi pada tujuan perusahaan dan hal tersebut menjadi proses dalam pemahaman karyawan dalam memahami misi suatu perusahaan.

Komunikasi yang melibatkan keterbukaan, transparansi dalam pertukaran informasi dua arah antara atasan atau bos dengan karyawan. Karyawan yang memiliki perilaku komuniksai yang positif akan menunjukkan keterikatan kerja dalam organisasi (Gallup, dalam Kang \& Sung, 2016). Dalam melakukan komunikasi dengan karyawan, perusahaan atau organisasi bisa secara khusus mempertimbangkan arus informasi, kecukupan informasi, dan interaksi dukungan sebagai faktor yang dapat berkontribusi terhadap keterikatan kerja (Rhee \& Moon, dalam Walden 2017). Isi komunikasi karyawan yakni karyawan menerima informasi yang memadai tentang apa yang sentral dan berbeda tentang organisasi mereka kemudian organisasi mampu mefasilitasi ketika karyawan diberikan informasi yang berguna tentang peran mereka dalam organisasi. Penelitian Walden, Jung dan Westerman (2017) mengenai hubungan dimensi dari komunikasi karyawan yakni arus informasi (information flow), kecukupan informasi (information adequacy), dan dukungan interaksi (interaction supportiveness) memiliki hubungan 
secara positif dengan keterikatan kerja.Selain peningkatan keterikatan kerja melalui komunikasi masih kurang berperan jika tidak dilakukannya melalui gaya kepemimpinan. Terkait peningkatan keterikatan kerja pada karyawan melalui kepemimpinan transformasional.kepemimpinan transformasional memacu karyawan untuk melakukan yang terbaik dari kemampuan karyawan atau individu dalam mengerjakan tugas-tugas sehingga karyawan merasa bersemangat dan mendedikasikan pekerjaan (Bass \& Avolio, dalam Men, 2014). Perilaku dari gaya kepemimpinan transformasional merupakan perilaku yang dijadikan panutan oleh bawahan atau karyawan. Gaya kepemimpinan ini memiliki potensi dalam meningkatkan keterikatan kerja pada karyawan khususnya karyawan milenial saat ini. Sebab gaya kepemimpinan ini lebih menekankan pada aspek-aspek hubungan atasan dengan bawahan karena terkait karakteristik milenial yang cenderung mementingkan adanya feedback, bimbingan dan arahan terlebih dahulu (Hershatter \& Epstein, dalam Thompson, 2012). Kekuatan pada pemimpin transformasional yakni mampu meningkatkan kepekaan terhadap kebutuhan pengikut (karyawan), dengan memberikan pengarahan langsung dalam membangun hubungan dan keterikatan kerja pada karyawan.

Adanya fenomena yang ada saat ini terkait karakteristik generasi kerja milenial dalam keterikatan kerja, membuat penelitian menarik untuk melihat peran dari kepemimpinan transformasional terhadap keterikatan kerja pada karyawan milenial ketika dipengaruhi oleh komunikasi sebagai aspek pendukung terhadap keterikatan kerja. Penelitian, ingin mengetahui peran mediator dari komunikasi khususnya untuk karyawan dalam meningkatkan keterikatan kerja pada karyawan milenial. Rumusan masalah dalam penelitian ini adalah apakah kepemimpinan transformasional memiliki peran terhadap keterikatan kerja dengan komunikasi sebagai variabel mediator.

\section{Rumusan Masalah}

Rumusan masalah dalam penelitian ini adalah ingin menguji apakah kepemimpinan transformasional memiliki peran terhadap keterikatan kerja dengan komunikasi sebagai variabel mediator.

\section{METODE PENELITIAN}

\section{Partisipan dan Prosedur Penelitian}

Penelitian ini teknik yang digunakan dalam pengambilan sampel yakni non-probability. Peneliti menggunakan jenis purposive sampling, yang artinya sampel ditentukan berdasarkan karakteristik subjek. Partisipan penelitian ini merupakan karyawan milenial dengan minimal pengalaman bekerja 6 bulan dan saat ini aktif sebagai karyawan.

Peneliti menyebar kuesioner secara online menggunakan Google Forms, sehingga partisipan penelitian dapat menyatakan persetujuan pengisian (informed consent) dan mengisi kuesioner menggunkana gadget. Hal tersebut guna mempermudah partisipan dalam mengisi kuesioner.

\section{Pengukuran}

Pada penelitian ini, digunakan 3 (tiga) alat ukur yang sudah di adaptasi oleh Song et a (2012, dalam jurnal yang berjudul "Role of Transformational Leadership in Effective Organizational Knowledge Creation Practices: Mediating Effects of Employee's Work Engagement") yakni Multifactor Leadership Questionnaire (MLQ) Form 6S, Ultrech Work Engagement Scale-17 UWES-17) yang dikembangkan oleh Schaufeli, et al (2006), Employee Communication Strategies yang dikembangkan oleh Rhee \& Moon pada tahun 2009. Peneliti melakukan uji 
validitas butir yang dilakukan kepada seluruh alat ukur dengan menggunakan Confirmatory Factor Analysis (CFA) pengujian validitas butir dilakukan untuk menguji apakah butir tes dapat dijadikan alat ukur dan menggunakan sesuai dengan tujuan pengukuran, dihitung berdasarkan simpangan baku skor butir dan korelasi skor butir dan skor kriteria. Pada model pengukuran CFA merupakan hubungan refleksi dari variabel yang teramati terhadap variabel laten yang mengkonfirmasi apakah variabel yang teramati merupakan butir yang merefleksikan variabel laten tersebut.

\section{HASIL DAN PEMBAHASAN}

Uji hipotesis dilakukan menggunakan teknik analisi model pengukuran item validasi antar dimensi dengan bantuan aplikasi Lisrel 8.80 full version. Berdasarkan hasil uji hipotesis kepemimpinan transformasional berhubungan positif dan signifikan dengan komunikasi karyawan dengan memiliki factor loading sebesar 0,84 dan nilai t-value $(13,85>1,96)$, komunikasi karyawan berhubungan positif dan signifikan dengan keterikatan kerja memiliki loading factor sebesar 0,45 dan nilai t-value $(4,36>1,96)$. Kemudian kepemimpinan transformasional berhubungan positif dan signifikan dengan keterikatan kerja, dengan komunikasi karyawan sebagai variabel mediator dengan factor loading sebesar 0,45 dan nilai tvalue 3,81(>3,81). Hasil data i menujukkan bahwa kepemimpinan transformasional memiliki hubungan secara langsung dengan keterikatan kerja akan tetapi hal pengaruh tersebut bisa berhubungan secara kuat jika ada variabel komunikasi sebagai mediator.Uji kecocokan model SEM menujukkan bahwa model yang digunakan dalam penelitian ini good fit. Berdasarkan nilai P-Value yakni $0,0398(<0,05)$ dengan tingkat kecocokan tidak fit namun, namun pada nilai index GFI 0,098 $(\geq 0,90)$, SRMR 0,86 $(\leq 0,05)$. Kemudian, pada index CFI $1,00(\geq 0,90)$ dan NNFI dengan hasil $1,00(\geq 0,90)$ maka bisa dikatakan hasil uji kecocokan model yang dikonsepkan pada penelitian ini didukung oleh data empiris lapangan.

\section{KESIMPULAN DAN SARAN}

Beberapa hal yang dapat disimpulkan dari penelitian ini. Pertama komunikasi karyawan memiliki peran sebagai mediator pada hubungan kepemimpinan transformasioanl dengan keterikatan kerja. Oleh sebab itu, bisa disimpulkan bahwa dengan komunikasi karyawan mampu memengaruhi keterikatan kerja milenial. Kedua, adanya hubungan secara langsung antara kepemimpinan transformasional dengan keterikatan kerja. Selain itu, penelitian ini juga melakukan peran dari masing-masing dimensi kepemimpinan transformasional dan komunikasi karyawan terhadap keterikatan kerja. Hasilnya dari dimensi-dimensi kepemimpinan transformasional hanya tidak memiliki hubungan yang signifikan terhadap keterikatan kerja yakni dengan nilai $t$ value kurang dari $(>1,96)$. Namun, dari dimensi-dimensi variabel komunikasi karyawan memiliki hubungan yang signifikan terhadap keterikatan kerja yakni dengan nilai $\mathrm{t}$ value $(>1,96)$. Berdasarkan penjelasan yang sudah dipaparkan tersebbut maka hipotesis dalam penelitian ini yakni terdapat hubungan kepemimpinan transformasional dengan keterikatan kerja secara langsung melalui komunikasi karyawan sebagai variabel mediator terbukti.

\section{Ucapan Terima Kasih}

Kami mengucapkan terima kasih dan penghargaan kepada seluruh partisipan yang telah berkontribusi dalam penelitian ini. 


\section{REFERENSI}

Bakker, Arnold, B., \& Bal, P, Matthijs. (2010). Weekly work engagement and performance a study among starting teachers. Journal of Occupational and Organizational Psychology, 83,189-206.

Bakker, A.B., \& Demerouti, E.(2008).Towards a model of work engagement. Career development international, 13(3), 209-223.

Bass, B.M., \& Riggio, R.E. (2006). Transformational leadership ( $2^{\text {nd }}$ ed).London: Lawrence Erlbaum Associates,Inc. retrieved from https://sci-hub.tw/10.1080/10887150701451312.

Dipo, S. (2016, Mei). Mengenal karakter 4 generasi: baby boomer,x,y dan milenial dalam pekerjaan. Di unduh dari https://glitzmedia.co/post/leisure/career-money/mengenalkarakter-4-generasi-baby-boomer-x-y-dan-milenial-dalam-pekerjaan.

Thompson, Charles., \& Gregory, Jane. (2012). Managing Millennials: A Framework for Improving Attraction, Motivation and Retention. The Psychologist-Manager Journal, 15: 237-246. DOI: 10.1080/10887156.2012.73044.

Rhee, Yunna., \& Moon, Beach. (2009). Organizational Culture and Strategic Communication Practice: Testing the Competing Values Model (CVM) and Employee Communication Strategies (ECS) Model in Korea. International Journal of Strategic Communication. 3:52-67. DOI: 10.1080/15531180802608386.

Rizkiani.Bonyta, \& Sawitri, Dian. (2015). Kepribadian Proaktif dan Keterikatan Kerja Karyawan PT PLN (PERSERO) Distribusi Jawa Tengah dan Daerah Istimewa Yogyakarta. Jurnal Empati. 4.(4). 38-43.

Schaufeli, W.B., Salanova,M., Gonzales-Roma,V.\&Bakker, A.B.(2002).The Measurement of Engagement and bournout: a two sample confirmatory factory analytic approach; journal of happinerss studies 3,71-92

Walden, Justin., Jung, Hwa., \& Westerman, Cathriene. (2017).Employee Communication, Job Engagement, and Organizational Commitment: A study of Members of the Millennial Generation. Journal of Public Relations Research. https://doi.org/10.1080/1062726X.2017.1329737. 